\title{
EDITORIAL
}

\section{Smoking and smoking cessation: a major role for the respiratory physician}

\author{
J.C. Yernault
}

Smoking is now universally recognized as the leading cause of two of the most frequent respiratory diseases, bronchial carcinoma and chronic obstructive pulmonary disease (COPD). Despite this evidence, the problems associated with nicotine addiction and smoking cessation occupy a relatively small space in The Journal and at our Annual Congress, which suggests that respiratory physicians are not active enough in antismoking campaigns. Moreover, a significant proportion of physicians still continue to smoke. It is with these observations in mind that discussions started between the European School of Respiratory Medicine (ESRM) and the American College of Chest Physicians (ACCP), in order to develop common actions against smoking.

At the 1993 Congress of the European Respiratory Society (ERS) in Firenze, it was proposed that a joint ERS-ACCP Committee on Smoking and Health would be created, which would be charged with the task of developing a statement to the world's physicians on: 1) smoking as an addiction; 2) the relationship between smoking and a variety of diseases; 3 ) the responsibility of physicians to help their patients stop smoking; and 4) the responsibility of physicians and their professional organizations to oppose the international tobacco industry in its attempts to increase tobacco use, especially use by children and young adults, in every country of the world.

The proposal was approved by the ACCP Board of Regents and the ERS Executive Committee, which suggested that, in order to make any statement even stronger, we should join forces with the American Thoracic Society (ATS). The Asian Pacific Society of Respirology (APSR), the Canadian Thoracic Society (CTS) and the International Union against Tuberculosis and Lung Diseases (IUATLD) were also invited to cooperate.

Correspondence: J.C. Yernault, Service de Pneumologie, Hôpital Erasme, route de Lennik 808, B-1070 Brussels, Belgium.
Each Society nominated its representative(s) to form the ad hoc Committee, which met for the first time in May 1994 on the occasion of the Boston ATS Annual Conference. A first draft of the document was quickly prepared and discussed in September 1994 during the Nice ERS Congress. Stephen Rennard acted as coordinating editor for the successive revisions, and after six iterations a final draft was produced which was formally approved by the official bodies of the six Scientific Societies, which together represent more than 30,000 respiratory physicians from all over the world. It is worth emphasizing that two people enthusiastically supported this initiative during its several stages, James Breeling ACCP Director of Health and Science Policy, and Paolo Paoletti former Head of the ERS Assembly on Epidemio$\log$.

At the same time that this declaration of war against tobacco by the respiratory world is being released [1], the United States medical [2, 3] and political authorities, including President Clinton himself, realize that nicotine addiction begins in children and young adults who constitute the preferred target for the tobacco industry's advertising and promotion campaigns, and that major efforts should be made to convince our youth not to start smoking. Time has come for respiratory physicians not only to counsel and help their patients to quit smoking (and to quit themselves!) but also to become strong advocates for tobacco control policies.

\section{References}

1. Smoking and health: a physician responsibility. A statement of the Joint Committee on Smoking and Health. Eur Respir J 1995; 8: 1808-1811.

2. Lynch BS, Bonnie RJ, eds. Growing up tobacco free: preventing nicotine addiction in children and youths. Washington, National Academy Press, 1994.

3. Kessler DA. Nicotine addiction in young people. $N$ Engl J Med 1995; 331: 186-189. 